\title{
Comparison of Interposition Ratios of Pink Muscle Fiber in Dorsal Ordinary Muscle among Various Marine Fishes
}

\author{
Osamu YAdA, ${ }^{1}$ Mutsuyoshi Tsuchimoto, ${ }^{1, *}$ Makoto Tomita,,${ }^{2}$ Abdul JABARsyah, ${ }^{1}$ Qin WANG, ${ }^{1}$ \\ Paula Andrea Gomez APABLAZA ${ }^{1}$ and Katsuyasu TACHIBANA ${ }^{1}$ \\ ${ }^{1}$ Laboratory of Fishery Nutritional Sciences, Graduate School of Marine Science and Engineering, Nagasaki University, Bunkyo-machi, \\ Nagasaki, 852-8131, Japan \\ ${ }^{2}$ Laboratory of Fishery Nutritional Sciences, Graduate School of Fisheries, Nagasaki University, Bunkyo-machi, Nagasaki, 852-8131, Japan
}

Received December 25, 2001; Accepted July 1, 2002

\begin{abstract}
The difference in interposition ratio of pink muscle fiber among various fish species was studied to learn its influence in dorsal ordinary muscle on the post-mortem change of $\boldsymbol{K}$-value. A remarkable mosaic pattern was exhibited in the interpositioned white and pink muscle fibers in many of the species. The relative number and area percentages of these fibers to all muscle fiber types differed greatly among fish species, and distributed from $12.9 \%$ to $56.53 \%$ in a number, and from $\mathbf{2 . 2 2} \%$ to $\mathbf{5 3 . 6 8 \%}$ in an area. The relationship between the area and numerical percentages had significantly high positive correlation. Size of the pink muscle fiber was somewhat smaller than that of white muscle fiber.
\end{abstract}

Keywords: dorsal ordinary muscle, interposition ratio of pink muscle fiber, size of pink muscle fiber, fish species

Organization of the dorsal skeletal muscle in fish is arranged in three distinct layers of dark muscle, intermediate muscle, and ordinary muscle. Each of these is organized in a single muscle fiber type as follows: red muscle fibers (Type I), pink muscle fibers, and the white muscle fibers (Type II), respectively (Johnston et al., 1974; Gill et al., 1982; Carpene et al., 1982; Hoyle et al., 1986). The red muscle fiber is small in diameter and relies on an aerobic form of metabolism, while the white muscle fiber has a large diameter and operates principally by anaerobic glycolysis. Functionally, the former is implicated in sustained slow swimming and the latter is in bursts of violent activity (Matsuoka \& Iwai, 1984). The white muscle fibers are subdivided into Types IIa and IIb, the IIa subtype being used not only for anaerobic metabolism but also for aerobic metabolism, and the IIb subtype especially for anaerobic metabolism in response to typical escape and attack movement; the pink muscle fiber is more particularly for aerobic metabolism than the IIa subtype (Jabarsyah et al., 1999a). The pink muscle fiber is characterized as fast contracting with intermediate resistance to fatigue and intermediate speed of shortening between red and white muscle fibers (Johnston et al., 1977). Most histochemical studies in fish muscle have involved these distinct layers, and only a few studies have dealt with the differences in fiber types in ordinary muscle among various fishes. Korneliussen et al. (1978) and Walesby and Johnston (1980) reported that a boundary region between the layers of intermediate muscle and ordinary muscle was not remarkable in the cod Gadus morhua, and that the Antarctic toleost Notothenia rosii had no pink muscle fiber in its locomotory muscles. In our previous study, we reported that there were not only white muscle fibers but also pink muscle fibers in the dorsal ordinary muscle of many fish species, and that the fiber type in

*To whom correspondence should be addressed.

E-mail: orenge@net.nagasaki-u.ac.jp this muscle was differed remarkably among species, between wild and cultured fish of the same species, and among regions along the length of the body and toward the neural spine (Jabarsyah et al., 1999a).

We also reported that the presence of pink muscle fiber in the ordinary muscle raised the maximum level in rigor mortis in various species (Jabarsyah et al., 1999b), and accelerated the temporal change of $K$-value (one of the freshness indices) in the carp (Yada et al., 2000). However, the influence of muscle fiber type on the temporal change of $K$-value, especially by the presence or absence of pink muscle fiber in the ordinary muscle has not yet been examined thoroughly. In the present study, we attempted to identify the difference in the interposition ratio of this fiber in the dorsal ordinary muscle.

\section{Materials and Methods}

Sample fish The twenty-seven fish species used as samples in this study are shown in Table 1. They were collected by fishing from the sea adjacent to the Sakishima Islands in Okinawa prefecture at a habitat temperature of $28^{\circ} \mathrm{C}$, and from the sea adjacent to Nagasaki prefecture at a habitat temperature of $17^{\circ} \mathrm{C}$ during the summer season. The only exception was one cultured species, red sea bream, which was purchased from a local fish farmer in Nagasaki prefecture during the same season. All sample fishes were transferred to the laboratory alive and held in a FRP tank with water similar to their habitat temperatures.

Histological preparation The fish were killed by cutting the hindbrain after anesthetizing them in seawater containing 100 ppm MS-222. Immediately after killing, several muscle blocks $(5 \mathrm{~mm} \times 5 \mathrm{~mm} \times 5 \mathrm{~mm}$ ) were cut off from the dorsal ordinary muscle underneath the lateral line near the mid-section of the fish's body length. The tissues were mounted on a cryostat chunk and embedded in a commercial mounting medium. They were frozen immediately for 10-15 s by immersion in isopentane, which was 
Table 1. Sample fish species used in the present study.

\begin{tabular}{|c|c|c|c|c|}
\hline Waters & Code number & Standard Japanese name & English name & Scientific name \\
\hline Sea adjacent & 101 & Nanyokaiwari & Kingfish & Caranx ferdau \\
\hline to Sakishima & 102 & Shimamochinouo & Barred wrasse & Cheilinus fasciatus \\
\hline Islands & 103 & Nokogiridai & Gold-lined sea bream & Gnathodentex aurolineatus \\
\hline \multirow[t]{10}{*}{ at $28^{\circ} \mathrm{C}$} & 104 & Shirodai & Drab large-eye bream & Gymnocranius japonicus \\
\hline & 105 & Amifuefuki & Half-belted emperor & Lethrinus semicinctus \\
\hline & 106 & Yosujifuedai & Blue and Yellow snapper & Lutjanus kasmira \\
\hline & 107 & Ojisan & Five-barred goatfish & Parupeneus trifasciatus \\
\hline & 108 & Kitsuneuo & Yellowstriped whiptail & Pentapodus macrurus \\
\hline & 109 & Nijihata & Flagtail rock-cod & Cephalopholis urodelus \\
\hline & 110 & Akahata & Black-tipped grouper & Epinephelus fasciatus \\
\hline & 111 & Ojirobarahata & A kind of rock cod & Variola albimarginata \\
\hline & 112 & Kotohiki & Threestriped tigerfish & Terapon jarbua \\
\hline & Total & 12 & & \\
\hline \multirow{16}{*}{$\begin{array}{l}\text { Sea adjacent } \\
\text { to Nagasaki } \\
\text { at } 17^{\circ} \mathrm{C}\end{array}$} & 201 & Bora & Striped mullet & Mugil cephalus \\
\hline & 202 & Maruaji & Round scad & Decapterus maruadsi \\
\hline & 203 & Maaji & Horse mackerel & Trachurus japonicus \\
\hline & 204 & Sasanohabera & Bambooleaf wrasse & Pseudolabrus japonicus \\
\hline & 205 & Ishidai & Japanese parrot fish & Oplegnathus fasciatus \\
\hline & 206 & Isaki & Threeline grunt & Parapristipoma trilineatum \\
\hline & 207 & Kagokakidai & Footballer & Microcanthus strigatus \\
\hline & 208 & Madai & Red sea bream (cultured) & Pagrus major \\
\hline & 209 & Masaba & Pacific mackerel & Scomber japonicus \\
\hline & 210 & Aigo & Dusky spinefoot & Siganus fuscescens \\
\hline & 211 & Izukasago & Izu scorpion fish & Scorpaena izensis \\
\hline & 212 & Usubahagi & Unicorn filefish & Aluterus monoceros \\
\hline & 213 & Umazurahagi & Black scraper & Navodon modestus \\
\hline & 214 & Kawahagi & Filefish & Stephanolepis cirrhifer \\
\hline & 215 & Kitamakura & Scribbled tody & Canthigaster rivulata \\
\hline & Total & 15 & & \\
\hline
\end{tabular}

cooled to its melting point $\left(-165^{\circ} \mathrm{C}\right)$ with liquid nitrogen, then placed in a refrigerated cryostat cabinet at $-25^{\circ} \mathrm{C}$ for $1 \mathrm{~h}$. Serial cross sections were then cut at a thickness of about $10 \mu \mathrm{m}$, mounted on glass cover slips and dried at room temperature.

Preincubation procedure The preincubation procedure of cross sections was carried out according to the method modified by Guth and Samaha (1969), which is commonly used in mammalian studies involving the discrimination of muscle fiber types in skeletal muscle. The method used most frequently to distinguish among muscle fiber types in mammalians is dependent on the histochemical actomyosin ATPase activity. By exposing frozen sections to acid or alkaline preincubation before staining for ATPase, it can be shown that the high-ATPase fibers (Type II) are alkali-stabile and acid-labile, whereas low-ATPase fibers (Type I) are acid-stabile and alkali-labile (Guth \& Samaha, 1969). In addition, the fibers having high-ATPase activity (Type II) could be further subdivided into Types IIa and IIIb. Brooke and Kaiser (1970) reported that two subtypes of Type II muscle fibers in adult humans could be distinguished successfully on the basis of the acid stability of actomyosin ATPase activity.

A series of seven cross sections was preincubated at each of various $\mathrm{pH}$ within the range of $\mathrm{pH} 4.20-\mathrm{pH} 4.80$ and $15^{\circ} \mathrm{C}$ for 0 , $0.5,1.0,1.5,2.0,3.0$, and $4.0 \mathrm{~min}$ in an acid preincubation solution of $0.1 \mathrm{M}$ potassium acetate buffer containing $18 \mathrm{mM} \mathrm{CaCl}_{2}$. Another series of seven cross sections was preincubated at each of various $\mathrm{pH}$ within the range of $\mathrm{pH} 10.35-\mathrm{pH} 10.80$ and $20^{\circ} \mathrm{C}$ for $0,5,10,15,20,25$, and $30 \mathrm{~min}$ in an alkaline preincubation solution of 0.1 м 2-amino-2-methyl-1-propernol (AMPro) buffer containing $18 \mathrm{mM} \mathrm{CaCl}_{2}$. This procedure involves selective inhibition of muscle fiber types by preincubation under either an acid or alkaline condition. If the $\mathrm{pH}$ of acid preincubation was lower or higher than the $\mathrm{pH}$ suitable for the same preincubation times, the actomyosin ATPase activities of muscle fiber types were completely activated or inactivated, and could not be distinguished. The $\mathrm{pH}$ inactivation of the ATPase activity was critically dependent on the $\mathrm{pH}$ of solution and also on the length of time for which the preincubation was carried out. Small variations in either $\mathrm{pH}$ or period made a great difference in the staining pattern of actomyosin ATPase. These two variations (preincubation $\mathrm{pH}$ and times) were interdependent. Therefore, we examined the combination of $\mathrm{pH}$ and time in all samples, and determined the most suitable condition.

After preincubation under acid and alkaline conditions, the sections were rinsed with $0.1 \mathrm{M}$ AMPro buffer ( $\mathrm{pH}$ 9.4) containing $18 \mathrm{mM} \mathrm{CaCl}_{2}$ and $50 \mathrm{mM} \mathrm{KCl}$.

Staining procedure The two previous series of rinsed cross sections were reacted at $20^{\circ} \mathrm{C}$ for $20 \mathrm{~min}$ in a medium of $0.1 \mathrm{M}$ AMPro buffer ( $\mathrm{pH}$ 9.40) containing $18 \mathrm{mM} \mathrm{CaCl}_{2}, 50 \mathrm{mM}$ $\mathrm{KCl}$, and $3.1 \mathrm{mM} \mathrm{ATP}$, according to the method described by Guth and Samaha (1969). The reacted sections were rinsed with distilled water and immersed in $1 \% \mathrm{CaCl}_{2}$ for $3 \mathrm{~min}$, then immersed in $2 \% \mathrm{CoCl}_{2}$ for 3 min. Finally, the production of phosphate from ATP under the remaining activity of actomyosin ATPase was displaced as cobaltous sulfide using $1 \%\left(\mathrm{NH}_{4}\right)_{2} \mathrm{~S}_{\mathrm{x}}$.

Estimation of number and area percentage of pink muscle fibers in dorsal ordinary muscle The relative values (\%) of number and area of pink muscle fibers to all muscle fiber types in the dorsal ordinary muscle were estimated using enlarged photographs of the alkaline preincubated section. The area percentage was measured by a tracing device linked to a digital computer (FLOVEL, measure unit MC 300, FLOVEL Co., Ltd., Tokyo).

\section{Results}

Muscle fiber types in dorsal ordinary muscle The opti- 
mum combination of $\mathrm{pH}$ and time for the discrimination of muscle fiber types was examined under both acid and alkaline preincubations for all sample fish species. Photographs of the staining results after both preincubations under optimum conditions are shown in Fig. 1. The results in all sample fish species are classified according to the composition of muscle fiber type in Table 2.

In the drab large-eye bream (code no. 104), all muscle fibers were stained very weakly at the same intensity both after acid preincubation at $\mathrm{pH} 4.50$ and $1.5 \mathrm{~min}$ and after alkaline preincubation at $\mathrm{pH} 10.40$ and $15 \mathrm{~min}$. Therefore, the ordinary muscle of this fish species was composed of only the IIa or IIb-like subtype of white muscle. This same composition of muscle fiber types was not observed in other sample species.

In the threestriped tigerfish (code no. 112), the muscle fibers exhibited a remarkable mosaic pattern after acid preincubation at

\section{Acid preincubation}

(pH4.50 and $1.5 \mathrm{~min}$ )

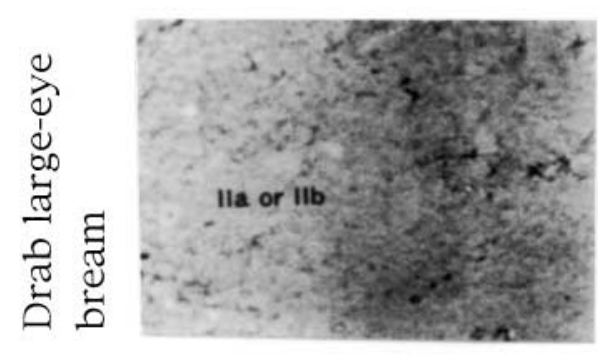

(pH4.50 and $1.5 \mathrm{~min})$

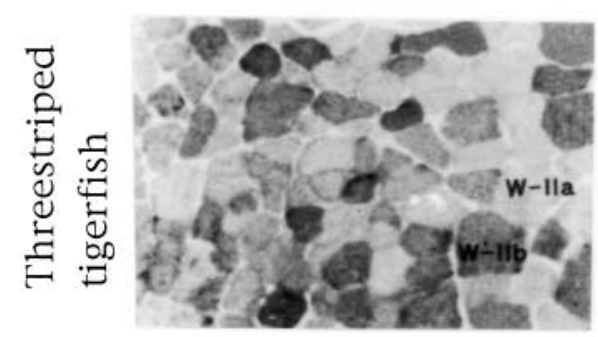

(pH4.32 and 2.0min)

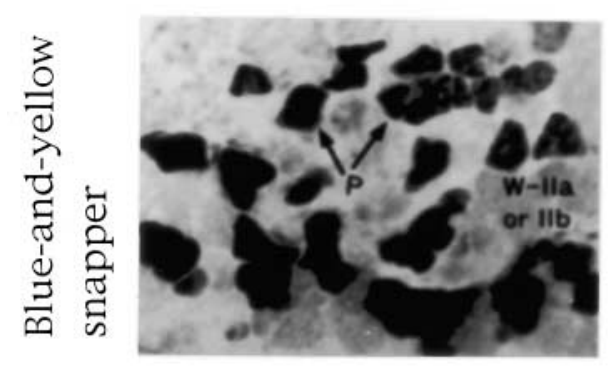

(pH4.50 and 2.0min)

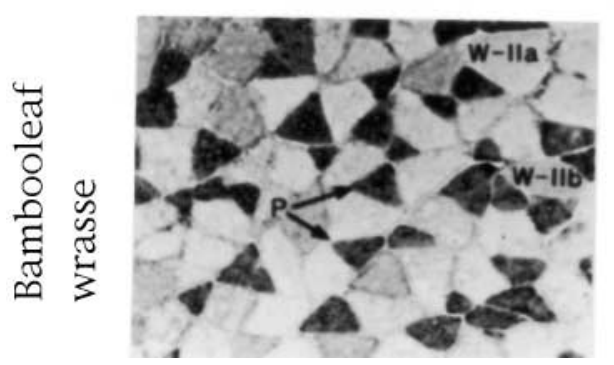

Alkaline preincubation
(pH10.40 and $15.0 \mathrm{~min})$

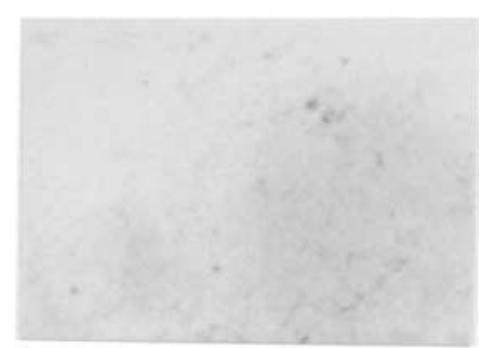

(pH10.40 and 20.0min)

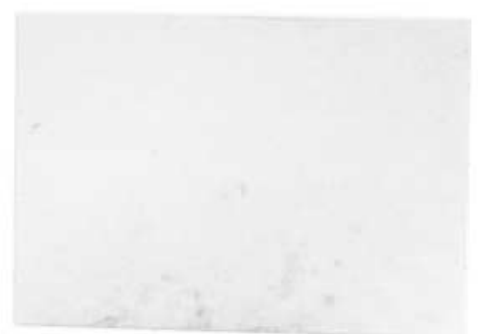

(pH10.40 and 20.0min)

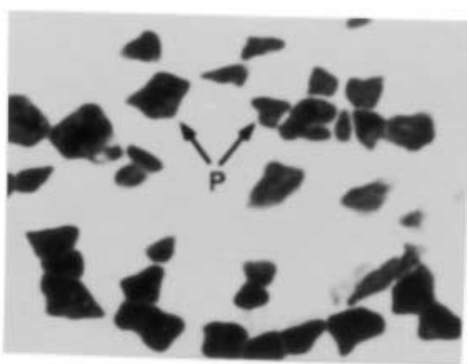

(pH10.40 and 20.0min)

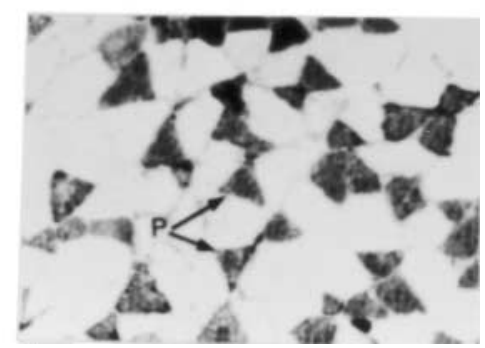

Fig. 1. Discrimination of muscle fiber types in dorsal ordinary muscle by stability of actomyosin ATPase activity after acid and alkaline preincubations for four fish species. The W-IIa, W-IIb, and P in photographs denote IIa-like subtype of white muscle, IIb-like subtype of white muscle, and pink muscle, respectively. 
pH 4.50 and $1.5 \mathrm{~min}$. Some fibers of similar size were stained strongly and observed among the unstained fibers. However, these were unstained in the same way as other muscle fibers after alkaline preincubation. They were therefore determined to belong to the IIb-like subtype of white muscle, and the ordinary muscle in this fish species was composed of IIa and Ilb-like subtypes of white muscle. The mosaic appearance after only acid preincubation was also seen in two fish species (code nos. 208 and 210) from Nagasaki as shown in Table 2.

In the blue and yellow snapper (code no. 106), the actomyosin ATPase activity remained on some muscle fibers not only after acid preincubation but also after alkaline preincubation, and the distinguishable mosaic pattern in these fibers was observed at both preincubations; all muscle fibers of acid stable actomyosin ATPase were also stable at alkaline preincubation. Therefore, the ordinary muscle in this fish species was composed of IIa or IIblike subtype of white muscle and pink muscle. The same composition of muscle fiber types was observed in nine fish species (code nos. 103, 105, 106, 107, 108, 209, 212, 213, and 214) from the Sakishima Islands and Nagasaki. However, the relative values of number and area of pink muscle fibers in all muscle fiber types exhibited a considerably different tendency among these species.

In the bambooleaf wrasse (code no. 204), the muscle fibers exhibited a remarkable mosaic pattern after both acid and alkaline preincubations, the same as the foregoing fish species. Although some fibers retained actomyosin ATPase activity after acid preincubation, these disappeared at an alkaline preincubation. Only much smaller muscle fibers were stained strongly after alkaline preincubation as well. Therefore, the ordinary muscle in this fish species was organized from IIa and Ilb-like subtypes of white muscle and pink muscle. The composition of three muscle fiber types the same as this species was observed in five other species (code nos. 101, 102, 109, 110, and 111) from the Sakishima Islands and in nine species (code nos. 201, 202, 203, 204, 205, 206, 207, 211, and 215) from Nagasaki. However, the rela-

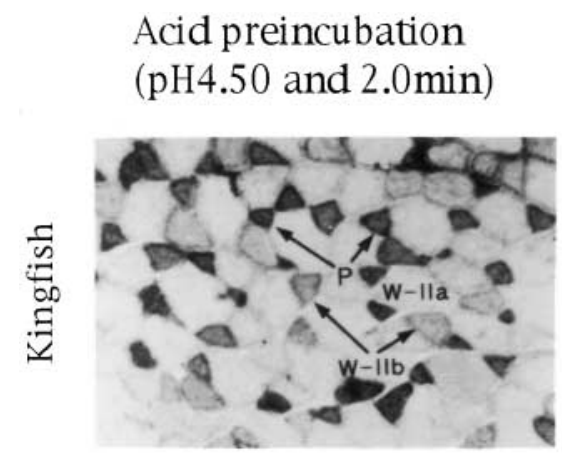

\section{Alkaline preincubation (pH10.40 and 20.0min)}

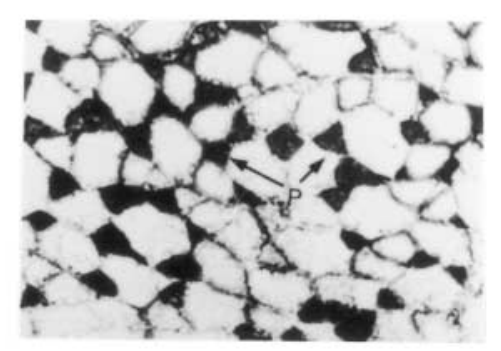

(pH10.40 and 20.0min)
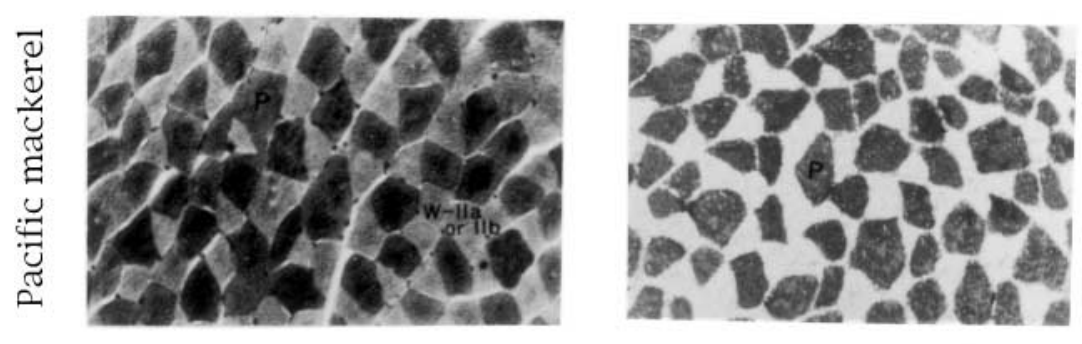

(pH4.50 and $2.0 \mathrm{~min})$

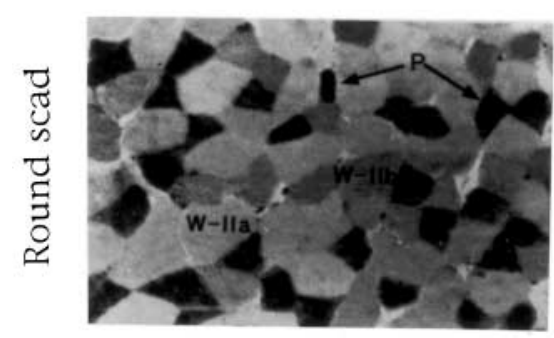

(pH10.40 and 20.0min)

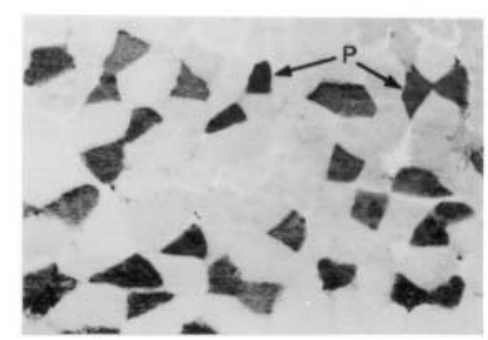

Fig. 2. Comparison of number and area of pink muscle fibers in dorsal ordinary muscle among three fish species. Indications of W-IIa, W-IIb, and P in the photographs are the same as in Fig. 1. 
Table 2. Classification of dorsal ordinary muscle to four compositions of muscle fiber types in various fish species.

\begin{tabular}{|c|c|c|c|}
\hline Waters & Muscle fiber type & Code number & Fish species \\
\hline \multirow{13}{*}{$\begin{array}{l}\text { Sea adjacent } \\
\text { to Sakishima } \\
\text { Islands } \\
\text { at } 28^{\circ} \mathrm{C}\end{array}$} & IIa or IIb & 104 & Drab large-eye bream \\
\hline & $\mathrm{IIa}+\mathrm{IIb}$ & 112 & Threestriped tigerfish \\
\hline & IIa or IIb+Pink & 103 & Gold-lined sea bream \\
\hline & & 105 & Half-belted emperor \\
\hline & & 106 & Blue and Yellow snapper \\
\hline & & 107 & Five-barred goatfish \\
\hline & & 108 & Yellowstriped whiptail \\
\hline & $\mathrm{IIa}+\mathrm{IIb}+$ Pink & 101 & Kingfish \\
\hline & & 102 & Barred wrasse \\
\hline & & 109 & Flagtail rock-cod \\
\hline & & 110 & Black-tipped grouper \\
\hline & & 111 & A kind of rock cod \\
\hline & & Total & 12 \\
\hline \multirow{17}{*}{$\begin{array}{l}\text { Sea adjacent } \\
\text { to Nagasaki } \\
\text { at } 17^{\circ} \mathrm{C}\end{array}$} & IIa or IIb & - & - \\
\hline & $\mathrm{IIa}+\mathrm{IIb}$ & 208 & Red sea bream (cultured) \\
\hline & & 210 & Dusky spinefoot \\
\hline & IIa or IIb+Pink & 209 & Pacific mackerel \\
\hline & & 212 & Unicorn filefish \\
\hline & & 213 & Black scraper \\
\hline & & 214 & Filefish \\
\hline & $\mathrm{IIa}+\mathrm{IIb}+\mathrm{Pink}$ & 201 & Striped mullet \\
\hline & & 202 & Round scad \\
\hline & & 203 & Horse mackerel \\
\hline & & 204 & Bambooleaf wrasse \\
\hline & & 205 & Japanese parrot fish \\
\hline & & 206 & Threeline grunt \\
\hline & & 207 & Footballer \\
\hline & & 211 & Izu scorpion fish \\
\hline & & 215 & Scribbled tody \\
\hline & & Total & 15 \\
\hline
\end{tabular}

IIa, IIb, and Pink denote muscle fiber types of IIa and IIb-like subtypes of white muscle and pink muscle fibers, respectively.

tive values of number and area of pink muscle fibers showed a considerably different tendency among these fish species as well.

Number and area of pink muscle fiber in dorsal ordinary muscle The remarkable differences of number and area of pink muscle fibers among the species sampled are shown in Fig. 2. The relative number among all muscle fiber types was more remarkably numerous in kingfish (code no. 101) and Pacific mackerel (code no. 209) than in round scad (code no. 202), while the relative area of these fibers to white muscle fibers was much smaller in the kingfish, but much larger in the Pacific mackerel, and similar in the round scad. Furthermore, the relative area of pink muscle fibers in the Pacific mackerel was larger than that in white muscle fibers. Thus, the relative number and area of these fibers to all muscle fiber types varied greatly among the sample fish species.

Relationship between area and number percentages of pink muscle fibers among all muscle fiber types The relationship between the area $(x)$ and number $(y)$ percentage values for the twenty-three fish species that interposed the pink muscle fiber is shown in Fig. 3. The relationship between the two values exhibited a significantly higher positive correlation $(r=0.804$ and $p<0.001$ ) with the exception of the Pacific mackerel (code no. 209). Furthermore, the calculated regression line moved parallel at the upper position distant from the $y=x$ line so that the values of both area and number are the same values. These results suggested that the size of pink muscle fiber in each species was somewhat smaller than that of white muscle fiber. However, the size in the Pacific mackerel (code no. 209) was farther below the $y=x$ line, suggesting, contrarily that the pink muscle fiber was the

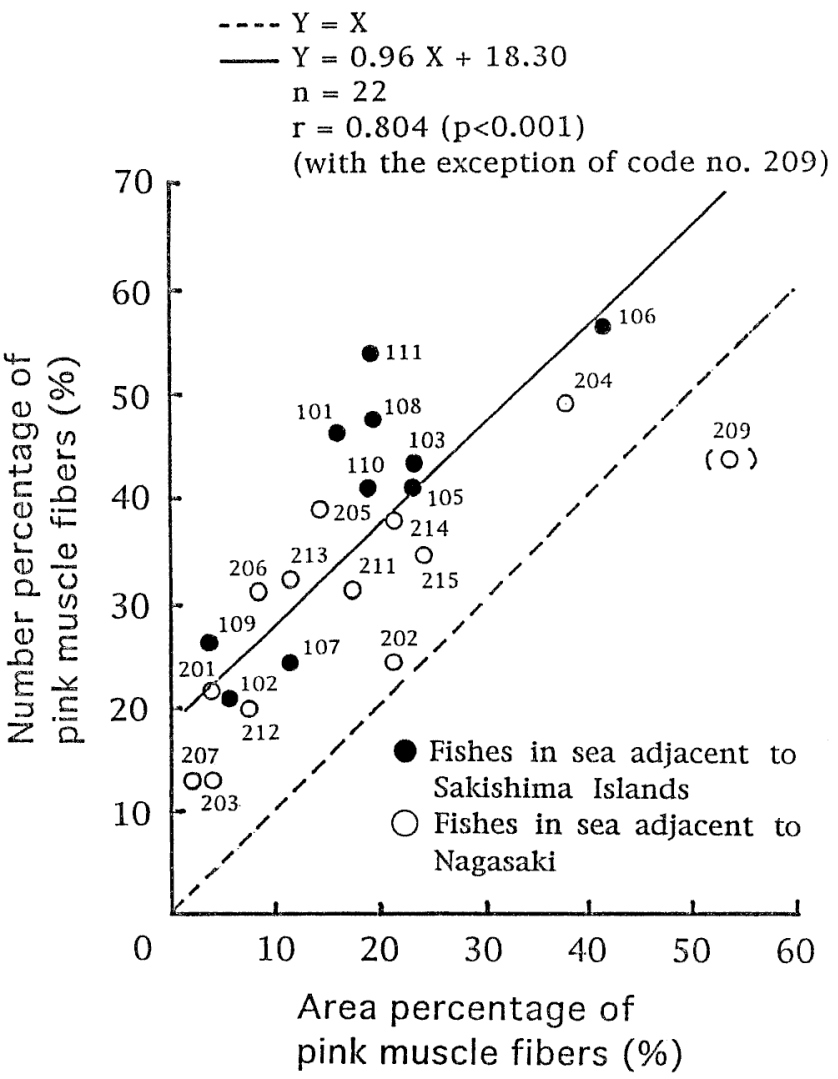

Fig. 3. Relationship between area and number percentages of pink muscle fibers in dorsal ordinary muscle for various fish species. The dotted line indicates the $y=x$ line where percentages of both area $(x)$ and number $(y)$ are the same values. •: fishes in sea adjacent to Sakishima Islands in Okinawa, $\bigcirc$ : fishes in sea adjacent to Nagasaki.

larger. Moreover, in the round scad (code no. 202), it was distributed nearly at the $y=x$ line, which suggested that the two fibers were very similar in size. Variola albimarginata (code no. 111), kingfish (code no. 101), and yellowstriped whiptail (code no. 108) were at positions above the calculated regression line, which suggested that the pink muscle fiber was remarkably smaller than the white muscle fiber.

Thus, the area percentage of pink muscle fibers against all muscle fiber types in the dorsal ordinary muscle differed greatly, and was much higher in the Pacific mackerel (code no. 209), the blue and yellow snapper (code no. 106), and the bambooleaf wrasse (code no. 204) within the range from $53.68 \%$ to $38.10 \%$. Other fish species fell within the range from $2.22 \%$ in the footballer (code no. 207) to $21.69 \%$ in the scribbled tody (code no. 215). The numerical percentage of pink muscle fibers was from $12.90 \%$ in the horse mackerel (code no. 203) and the footballer (code no. 207) to $56.53 \%$ in the blue and yellow snapper (code no. 106).

\section{Discussion}

The pink muscle fiber is recognized in the dorsal ordinary muscle of many fish species and exhibits a mosaic pattern among the white muscle fibers (Figs. 1 and 2). Findings similar to this have been reported in the grey mullet by Carpene et al. (1982), the cod by Korneliussen et al. (1978), the roach by Kilarski (1990), and a number of fish species by both Mosse \& Hudson 
(1977), and our own previous studies (Jabarsyah et al., 1999a, 1999b). The present study clarified that the number and area percentages of pink muscle fibers against all kinds of muscle fiber types in the dorsal ordinary muscle were considerably different among fish species, and fell within ranges of from $12.90 \%$ to $56.53 \%$ and from $2.22 \%$ to $53.68 \%$, respectively (Fig. 3). We further recognized there was no pink muscle fiber in dorsal ordinary muscles in four of the species we sampled (Table 2 and Fig. 1). These differences were not caused by the difference of habitat temperature (Table 2 and Fig. 3), but the causative factors are still unknown. We speculate that it may be connected with not only a difference in genes but also swimming ability, because the muscle fiber type in the dorsal ordinary muscle differed between the cultured and wild specimens of the red sea bream (Jabarsyah et al., 1999a), and metabolism is more aerobic in pink than in white muscle fiber.

We reported in previous studies that the histochemical actomyosin ATPase activity of pink muscle fibers in the mosaic pattern of ordinary muscle was very stable in both acid and alkaline preincubations, which was similar to that of these fibers in the intermediate part of the muscle (Jabarsyah et al., 1999a), and also that the glycogen content in the pink muscle fibers in ordinary muscles was considerably higher, which was also similar to that in the intermediate part of the muscle (Yada et al., 2000). Namely, the histochemical characteristics of pink muscle fibers in both ordinary and intermediate muscles were very similar. The same findings were reported in the rainbow trout (Johnston et al., 1975 ), and we reported that the temporal change of $K$-value in the dorsal ordinary muscle of carp was accelerated by the interposition of pink muscle fibers (Yada et al., 2000). It was therefore thought that the interposition of pink muscle fibers into the ordinary muscle might cause a temporal change in $K$-value (one item of the freshness index), which might be explain the difference in the increasing $K$-value rate among fish species.

\section{References}

Brooke, M.H. and Kaiser, K.K. (1970). Muscle fiber types: how many and what kind? Arch. Neurol., 23, 369-379.

Carpene, E., Veggetti, A. and Mascarello, F. (1982). Histochemical fibre types in the lateral muscle of fishes in fresh, brackish and salt water. J. Fish Biol., 20, 379-396.

Gill, H.S., Weatherley, A.H. and Bhesania, T. (1982). Histochemical characterization of myotomal muscle in the bluntnose minnow, Pimephales notatus Rafinesque. J. Fish. Biol., 21, 205-214.

Guth, L. and Samaha, F.J. (1969). Qualitative differences between actomyosin ATPase of slow and fast mammalian muscle. Exp. Neurol., 25, 138-152.

Hoyle, J., Gill, H.S. and Weatherley, A.H. (1986). Histochemical characterization of myotomal muscle in the grass pickerel, Esox americanus vermiculatus (LeSeuer), and the muskellunge, E. masquinongy (Mitchell). J. Fish. Biol., 28, 393-401.

Jabarsyah, A., Tsuchimoto, M., Kozuru, Y., Misima, T., Yada, O. and Tachibana, K. (1999a). Discrimination of muscle fiber types in ordinary muscle by actomyosin ATPase activity and its comparison among various fishes and muscle parts. Fish. Sci., 65, 291-299.

Jabarsyah, A., Tsuchimoto, M., Kozuru, Y., Misima, T., Yada, O. and Tachibana, K. (1999b). The influence of pink muscle fiber in ordinary muscle of fishes on the rigor mortis progress. Fish. Sci., $\mathbf{6 5}$, 472-477.

Johnston, I.A., Patterson, S., Ward, P. and Goldspink, G. (1974). The histochemical demonstration of myofibrillar adenosine triphosphatase activity in fish muscle. Can. J. Zool., 52, 871-877.

Johnston, I.A., Ward, P.S. and Goldspink, G. (1975). Studies on the swimming musculature of rainbow trout; I. Fiber types. J. Fish. Biol., 7, 451-458.

Johnston, I.A., Davison, W. and Goldspink, G. (1977). Energy metabolism of carp swimming muscles. J. Comp. Physiol., 114, 203-216.

Kilarski, W.M. (1990). Histochemical characterization of myotomal muscle in the roach, Rutilius rrutilus (L). J. Fish Biol., 36, 353-362.

Korneliussen, H., Dahl, H.A. and Paulsen, J.E. (1978). Histochemical definition of muscle fibre types in the trunk musculature of a toleost fish (Cod, Gadus morhua, L). Histochemistry, 55, 1-16.

Matsuoka, M. and Iwai, T. (1984). Development of the myotomal musculature in the red sea bream. Bull. Jpn. Soc. Sci. Fish., 50, 29 35.

Mosse, P.R.L. and Hudson, R.C.L. (1977). The functional roles of different muscle fiber types; a behavioral, anatomical and histochemical study. J. Fish Biol., 11, 417-430.

Walesby, N.J. and Johnston, I.A. (1980). Fibre types in the locomotory muscles of an Antarctic toleost, Notothenia rossii: A histochemical ultrastructural and biochemical study. Cell Tissue Res., 208, 143164.

Yada, O., Tsuchimoto, M., Wang, Q., Apablaza, P.A.G., Jabarsyah, A. and Tachibana, K. (2000). Differences of muscle fiber type and temporal change of K-value among parts toward depth of dorsal ordinary muscle in carp (cultured). Fish. Sci., 66, 147-152. 